\title{
Echogenic Catheters and Embryo Transfer Standardization
}

\author{
Maria Teresa Urbina ${ }^{1}$, Isaac Benjamin ${ }^{1}$, Randolfo Medina ${ }^{1}$, Jorge Lerner $^{1}$ \\ ${ }^{1}$ Unidad de Fertilidad UNIFERTES, Caracas, Venezuela
}

\begin{abstract}
Objective: 1 .To describe the standardization process and protocols of the ET method at our center.

2.To compare the performance of non-echogenic catheters with echogenic catheters during ultrasound-guided ET.

Methods: Retrospective analysis of 2630 ET performed at UNIFERTES during 1997-2014, to describe standardization process and to compare the percentage of difficult ET between echogenic and non-echogenic catheters. We tested 17 non-echogenic and three echogenic catheters. Results: Many variables were associated with the ease of ET: informed patients, waiting time for the procedure, speculum use, clinical touch, uterine contractions, cervical mucus removal, presence of blood before or after the procedure, full bladder, ultrasound guidance, uterocervical angle, mock transfer, catheter type (soft or hard, echogenic or non-echogenic, with stylet or not), catheter loading technique, duration of embryo loading (time interval since the embryos were removed from the incubator for loading until the catheter is passed to the physician), transfer procedure (time interval from the catheter was handed to the physician until the embryos were discharged in the uterus), catheter tip placement, retained embryos, bed rest after ET, operator's proficiency. The diversity of catheters used and the percentage of difficult transfers decrease as the use of echogenic catheters increases. This process is necessary to minimize variation, ensure high quality, safe and evidence-based practice, and improve outcomes.

Conclusions: To standardize the ET method allowed a quicker and easier transfer. The use of echogenic catheters simplified ET procedures guided by abdominal ultrasound.
\end{abstract}

Keywords: Echogenic catheter, Embryo, Transfer.

\section{INTRODUCTION}

The accurate description of materials and methods is essential for scientific reporting. A good description of a study's methodology allows others to replicate the experiment and verify previous findings. Scientific reports can often be inadequate, even in the case of high-quality studies such as randomized controlled trials (RCT) (Gambadauro \& Navaratnarajah, 2015; Peron et al., 2012; Turner et al., 2012; Wang et al., 2011).

In fertility treatments there have been great improvements in ovarian stimulation protocols and embryo culture, but few advances in embryo transfer (ET) techniques, partly because papers seldom describe ET methods precisely, as reported by Gambadauro \& Navaratnarajah (2015) in a cross-sectional analysis of RCT. There is need for adequate scientific reports describing the ET method accurately in order to allow for reproducibility (one of the principles of the scientific method), and allow standardization (one of the aims of this study). This process is necessary to decrease variation, ensure high quality, safe and evidence-based practice, and improve outcomes (ACOG, 2012; Gambadauro \& Navaratnarajah, 2015).

The scant evidence available indicates that different methods, tools and operators of ET can influence pregnancy rates (Karande et al., 1999; Mains \& Van Voorhis, 2010). Many variables have been associated with the ET out- come: informed patients, waiting time for the procedure, speculum use, clinical touch, uterine contractions, cervical mucus removal, presence of blood before or after the procedure, full bladder, ultrasound (US) guidance, uterocervical angle, mock transfer, catheter type (soft or hard, echogenic or non-echogenic, with stylet or not), catheter loading technique, duration of embryo loading (time interval since the embryos were removed from the incubator for loading until the catheter is passed to the physician), transfer procedure (time interval from the catheter was handed to the physician until the embryos were discharged in the uterus), muscle relaxants use, catheter tip placement, retained embryos, bed rest after ET, bacterial contamination and operator's proficiency (Abou-Setta et al., 2007; Brown et al., 2010; Gambadauro \& Navaratnarajah, 2015).

Among them, US guidance and the choice of catheter seem to be the most important variables associated with better outcomes of ET. Both significantly affect the success rate of ET at meta-analysis (Gambadauro \& Navaratnarajah, 2015; Brown et al., 2010; Bucket, 2006).

The "ease" of ET is correlated with pregnancy outcome. An evidence-based recommendation is to avoid difficult transfers, as they are associated with poorer outcomes (Mains \& Van Voorhis, 2010). Compared with easy transfers, difficult ones have been shown to relate significantly with lower pregnancy rates (PR) and implantation rates (IR). One study on 4,807 ETs found a 1.7-fold higher PR in easy or intermediate transfers than in difficult transfers $(P<.0001 ; 95 \%$ Confidence Interval 1.3-2.2) (Mansour et al., 1990).

The "difficulty" of a transfer is often subjectively described as transfers that are time consuming, with multiple attempts, including different catheters, require a difficult transfer catheter, need a tenaculum, cause cramping, discomfort or bleeding. Traumatic transfers can interfere with implantation through the stimulation of uterine contractions (Fanchin et al., 1998), initiated by fundal contact or cervical manipulation, and associated with the release of prostaglandins and oxytocin (Dorn et al. 1999). Presence of blood in the catheter is also associated with decreased $P R$ and a higher incidence of retained embryos (Goudas et al. 1998; Sallam et al. 2003). The most common reasons for a difficult transfer are cervical stenosis or a large degree of anteversion/retroversion or anteflexion/retroflexion of the uterus (Mansour \& Aboulghar, 2002; Mansour, 2012).

Success of ET is also operator dependent, as has been shown for a RCT comparing two catheters and studying the interactions between catheters and operators. (Karande et al., 1999; Yao et al., 2009).

Meldrum et al. (1987) were among the first to suggest that a meticulous ET technique is essential for IVF success. The use of standardized protocols is an important factor for a successful ET.

The objectives of this study were:

1 . To describe the standardization process and protocols of the ET method at our center.

2. To compare the performance of echogenic and non-echogenic catheters during US-guided ET. 


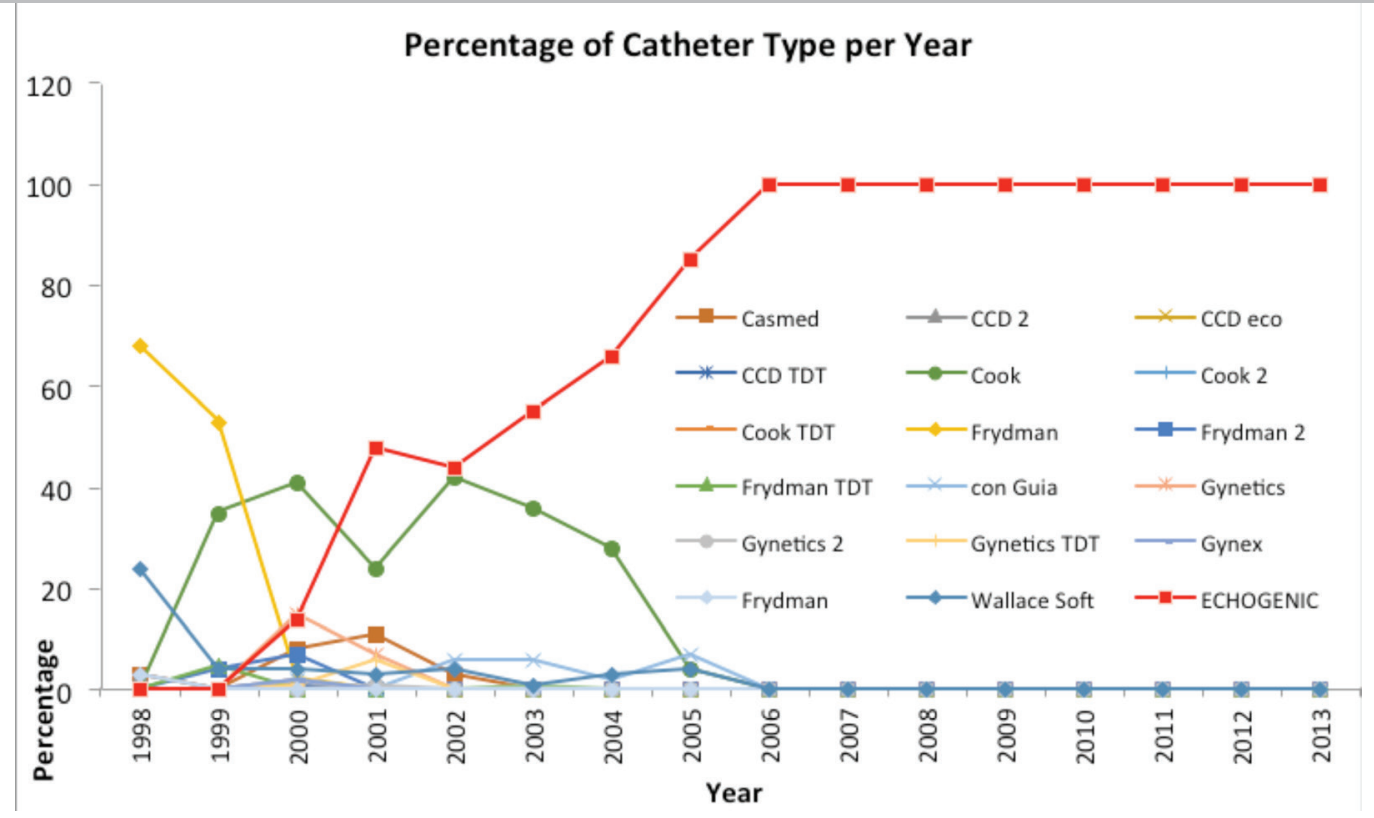

\section{MATERIAL AND METHODS}

Retrospective analysis of 2630 ET performed at UNIFERTES during 1997-2014, to describe standardization process and to compare the percentage of difficult ET between echogenic and non-echogenic catheters.

The ET catheters used were:

Non-echogenic ET catheters:

1. Casmed Dual Lumen (Casmed International, UK)

2. CCD Clasic Ultrasoft (Laboratoire CCD, France)

3. CDD Stylet with an outer sheath (Laboratoire CCD, France)

4. CCD TDT (Laboratoires CCD, París)

5. Cook Sydney IVF (Cook Medical, USA)

6. Cook Soft-Pass (Cook Medical, USA)

7. Cook Soft-Trans (Cook Medical, USA)

8. Frydman Classic 4.5 (Laboratoire CCD, France)

9. Frydman Soft 4.5 with guide (Laboratoire CCD, France)

10. Frydman Set TDT (Laboratoire CCD, France)

11. Frydman Classic Ultrasoft (Laboratoire CCD, France)

12. Gynex (Gynex Corporation, USA)

13. Gynetics Delphin (Soft) (Gynetics Medical Products, Belgium)

14. Gynetics Emtrack-A (Soft and solid) (Gynetics Medical Products, Belgium)

15. Gynetics for difficult transfers Gynetics Medical Products 16. Tight Difficult Transfer (TDT) (Irvine Scientific, USA)

17. Wallace Soft (Smiths Medical, UK)

\section{Echogenic catheters}

1. Cook Echo Tip (Cook Medical, USA)

2. Wallace Sureview (Smith-Medical,UK)

3. Wallace Sure-Pro Ultra (Smith-Medical,UK)

The tuberculin syringe that we use to attach the ET catheter was latex free, contain no rubber, no silicone oil, styrene or DEHP and was DNA free (Norm Ject, Air-Tite Products Co., Inc., USA). We tested it to confirm it is not embryo-toxic.

The standardization process to develop these ET protocols were collaborative, inclusive and multidisciplinary. The choice of the catheter was decided by operator's preference, frequently after trying different catheters on several attempts of mock transfers.

We divided the analysis into two phases:
Phase I: Which comprised 841 ET performed with a wide variety of ET catheters ( $n=18$, including echogenic and non-echogenic) in women averaging $35.2 \pm 5.5$ years old, between 1997 and 2005.

Phase II: Which comprises 1789 ET performed with only echogenic catheters $(n=3)$, in women averaging 36.4 \pm 5.5 years old, between 2006 and 2014 .

- $\quad$ To reduce the possible effect of human factor as a variable, all ETs were performed by two physicians whose clinical pregnancy rates (CPR) and live birth rates (LBR) were not significant different from each other. The efficacy of the ET has been shown to be operator dependent (Karande et al., 1999; Yao et al., 2009).

- $\quad$ ETs were performed under abdominal US guidance, in dorsal lithotomy position as an outpatient procedure without anesthesia. A second operator checked with the US that the bladder was full enough. If so, and the patient was not feeling discomfort, the first operator gently inserted the speculum into the vagina for visualization of the cervix.

- The cervix was cleaned with a moist gauze and a tuberculin syringe filled with culture medium to remove cervical mucus in Phase I, and with a $10 \mathrm{cc}$ syringe filled with saline medium in Phase II.

- $\quad$ The mock transfer catheter was inserted up to the cervical inner os, avoiding the induction of contraction and traumatisms to the uterus. This insertion was done under US guidance, checking endometrium thickness, uterocervical angle and distance between the inner os and the endometrial fundus.

- The transfer catheter was then loaded with the embryo(s) with the "three drop technique" (air bubble-30 $\mu$ l culture medium- embryo-air bubble) in Phase I. In Phase II we use the "three drop technique" or the fluid column technique.

- The loaded ET inner catheter was inserted using the outer sheath, into the cervical canal. From there on, only the inner catheter was advanced into the uterine cavity. The embryo(s) was deposited by applying gentle pressure, at $1.0-1.5 \mathrm{~cm}$ 


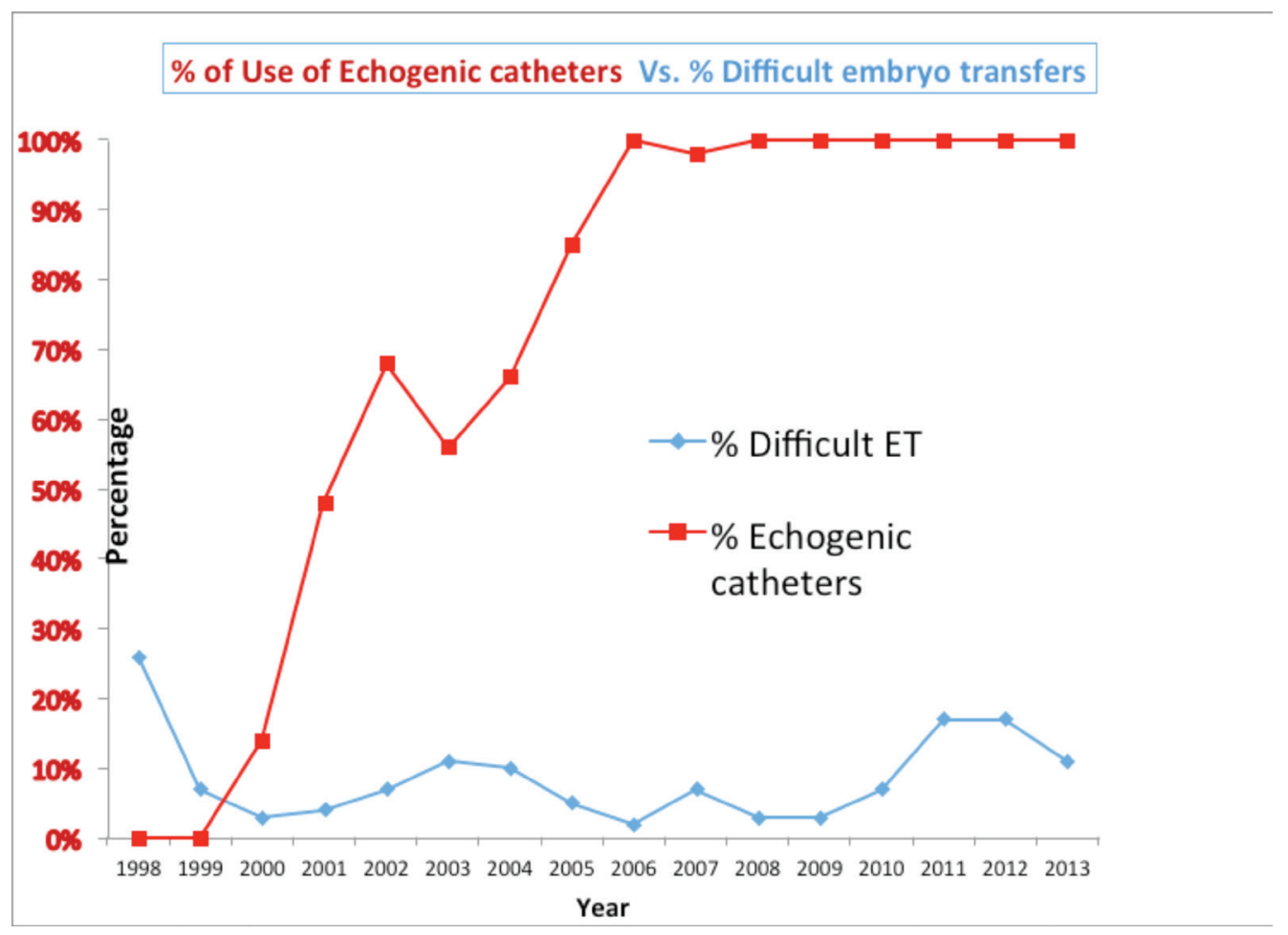

from the fundus in Phase I, $1.5-2.0 \mathrm{~cm}$ in Phase II. Finally, the physician $180^{\circ}$ rotated the catheter, paused, slowly withdrawn and paused, keeping the finger pressure on the plunger of the syringe, to minimize the effects of negative pressure.

- $\quad$ Once verified that the embryo(s) was not retained in the catheter, the speculum was withdrawn and the patient bed-rested during 30 minutes in Phase I and 20 minutes in Phase II.

- Embryo transfer difficulty was graded by agreement between the clinician and the biologist, considering consuming time, patient discomfort, tenaculum use, retained embryos and blood presence (within the tip of the catheter was interpreted as damage to the endometrium; while outside the tip or at the outer sheath as damage to the cervix and not the endometrium as suggested by De Placido et al., 2002). The data-driven process was constantly monitored.

\section{RESULTS}

During the Phase I (1998-2005), we had to stock a wide diversity of catheters $(n=18)$ to satisfy physician's preferences. This situation changed with the development of echogenic catheters. During Phase II (2006-2014) we used Echogenic catheters exclusively, according with the physician's preference. The echogenic catheters were consistently seen with US guidance, facilitating the standardization of ET. Currently, all ET are performed exclusively with echogenic catheters (Figure 1)

At the beginning of Phase I, percentages of difficult transfer were high averaging over $20 \%$, compared with the literature. Since 2000, when the echogenic catheter COOK Echo Tip was available, the percentage of difficult transfer decreases as it increases the preference for the use of COOK EchoTip. From 2006 on, when the use of echogenic catheters became exclusive, the percentage of difficult transfer dropped to about $10 \%$. Since 2007 , we used other echogenic catheters: Wallace Sureview, and Sure-Pro UItra, with similar results (Figure 2 ).

\section{DISCUSSION}

\section{Standardization}

We identified the relevance of several factors while standardizing the protocol of ET. Testing a wide variety of technique and catheters were intended to improve the ET method through 16 years at UNIFERTES.

The best strategy to standardize the ET protocol in UNIFERTES was to consider it a crucial step in IVF treatment, and to understand it like a comprehensive and multidisciplinary procedure, which comprises of the patient, the physicians, biologists, nurses and the emotional support team as recommended by ACOG (2012).

The second best strategy was the visualization of the tip of the catheter, to atraumatically deposit the embryo into the uterine cavity.

On the following paragraphs we discuss each step of the standardization process and the current ET protocol (Table 1):

- $\quad$ Patients understanding: Uterine contraction frequency at the time of ET is correlated with anxiety levels (Fanchin et al., 1998). The clinician provided a good explanation about the procedure, because the patients understanding alleviates her anxiety and facilitates the ET.

- Double check of patient's name: It is essential to avoid mistakes (Antunes et al., 2015). The nurse checked verbally that the patient's name and identification are the same that in the written register, before her entrance to the embryo transfer room. Once there, the nurse double checked the name, and inform patient's name to the ET staff (as recommended by Antunes et al., 2015). This step also contributed to increasing confidence and relaxation of the patient.

- $\quad$ Full bladder and waiting time for the procedure: US guidance requires a full bladder and a second operator. The full bladder straightens the uterocervical angle facili- 


\begin{tabular}{|c|c|c|}
\hline Checklist & Phase I & Phase II \\
\hline Patient understanding & Yes & Improved \\
\hline Double check of patient's name & Yes & Yes \\
\hline $\begin{array}{l}\text { Full bladder and waiting } \\
\text { time for the procedure }\end{array}$ & Variable & Reduced \\
\hline Cervix cleaning & $\begin{array}{c}\text { With a moist gauze, tuberculin syringe } \\
\text { and catheter, with ET medium, } \\
\text { without antiseptics }\end{array}$ & $\begin{array}{c}\text { With a moist gauze, } 10 \mathrm{cc} \\
\text { syringe and saline medium, } \\
\text { without antiseptics }\end{array}$ \\
\hline US guidance & Yes & Yes \\
\hline Mock transfer & Yes & Yes \\
\hline Gentle manipulation & Yes & Yes \\
\hline Tenaculum & Yes, when needed. & No \\
\hline Catheter loading technique & Three drop & $\begin{array}{l}\text { Fluid column or three } \\
\text { drop technique }\end{array}$ \\
\hline Load volume & $50-60 \mu l$ & 20-30 $\mu \mathrm{l}$ \\
\hline $\begin{array}{l}\text { Catheter types } \\
\mathrm{N}^{\circ}\end{array}$ & $\begin{array}{l}\text { A wide variety of catheters } \\
\qquad(n=18)\end{array}$ & $\begin{array}{l}\text { Echogenic catheters } \\
\text { exclusively }(n=3)\end{array}$ \\
\hline Embryo loading time & Minimum & Minimum \\
\hline Ejection speed & Minimum & Minimum \\
\hline ET procedure time & Variable & Reduced \\
\hline Distance from fundus & $1-1.5 \mathrm{~cm}$ & $1.5-2 \mathrm{~cm}$ \\
\hline Withdraw of ET catheter & Slow & Slow \\
\hline Checking & Yes & Yes \\
\hline Bed rest & 30 minutes & 20 minutes \\
\hline Emotional support & No & Yes \\
\hline
\end{tabular}

tating the advancement of the catheter (important in cases of anteflexed and anteverted uterus), but it can cause some patient discomfort, bladder contractions, cramping, pain, anger and anxiety. We did our best to shorten the waiting time for the procedure.

- Cervix cleaning: Several studies have shown that the presence of cervical mucus on the ET catheter decreases the implantation and pregnancy rates (McNamee et al., 1997; Tiras \& Cenksoy, 2014). It may cause embryo retention due to mechanical blockage of the catheter opening. The exhaustive cleaning of the cervix avoids the embryo retention into the catheter. The cervical mucus can be removed with a sterile gauze or cotton swab, with gentle irrigation with saline or culture media, and it can also be aspirated using a sterile syringe (McNamee et al., 1997; Michael \& Ahmady, 2005; Tiras \& Cenksoy, 2014). In Phase I, we used to clean the cervix using a catheter connected to a tuberculin syringe with culture medium. In Phase II, we used a $10 \mathrm{cc}$ syringe with saline media to increase fluid pressure and volume, hence allow a more exhaustive cleaning of the cervix.

- US guidance: Several meta-analyses (Abou-Setta 2007, Buckett 2003, Sallam \& Sadek 2003) and a Cochrane review showed that the US guidance improves the live birth/ongoing and pregnancy rates compared with the clinical touch (Brown et al., 2010; Tiras \& Cenksoy, 2014). US Guidance in ET allows to address the catheter, verify the uterocervical angle, avoid uterine contractions and guide the catheter tip to the endometrium surface, minimizing endometrial damage. On the contrary, clinical touch may disrupt the endometrium and induce uterine contractions. Some authors proposed Transvaginal ultrasound-guided embryo transfer (Woolcott \& Stanger, 1997).
In both phases of this study, we used abdominal US guidance:

-In Phase I, we visualized the air bubbles in the catheter loaded with the three drops technique and discharge the embryos at $1.0-1.5 \mathrm{~cm}$ without touching the fundus.

-In the Phase II, the echogenic catheters facilitated the visualization, in order to deposit the embryos at 1.5-2.0 $\mathrm{cm}$ without touching the fundus.

- Mock transfer: Mansour et al. (1994) studied 335 women randomized to a pre-cycled mock transfer or no mock transfer and found that ET was difficult in 50 $(29.8 \%)$ of cases when no mock transfer was performed versus when it was no difficult transfer. Sallam et al., 2002 showed that ultrasound measurement of the utrerocervical angle before ET significantly diminishes the frequency of difficult transfers and increases the CPR and IR. Moulding the ET catheter according to the degree of angulation, prevent bleeding and ease the ET. We performed two mock transfers, pre-cycled and just before the actual ET, using a sterile soft ET catheter of the same type as the actual ET catheter. It was inserted under US guidance, to the cervical inner os, avoiding to induce contractions and traumatisms to the uterus. The mock transfer was useful also to check uterocervical angle, endometrium thickness and the depth of the uterine cavity (Egbase et al., 2000).

- Gentle insertion: Lesny et al. (1999) reported that a tenaculum application to the cervix increases uterine contractions, which affect embryo implantation. The use of a tenaculum was associated with an elevation in oxytocin level, which remained elevated until the end of the ET procedure. Oxytocin induces uterine contractions. Without using a tenaculum, no increase in serum oxytocin level was observed (Mansour \& Aboulghar, 2002). 
Table 2. Embryo transfer tips

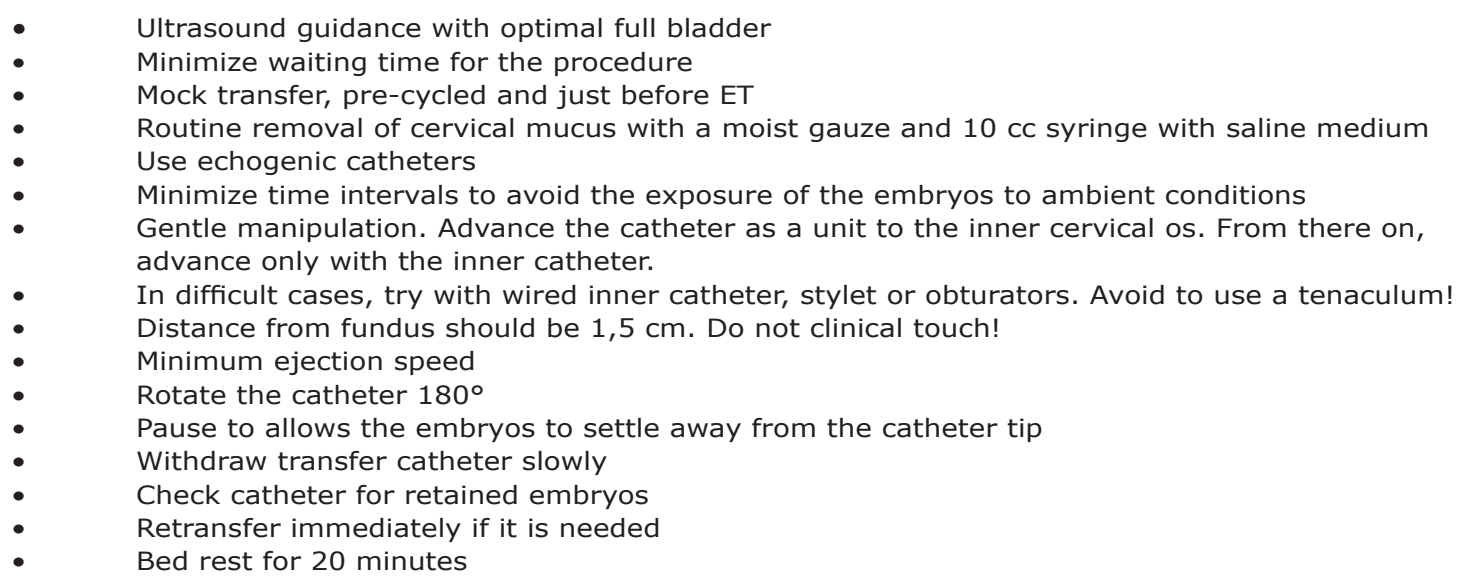

When using coaxial catheters, both, inner and outer sheaths advance as a unit, up to the inner cervical os. From there on, only the inner catheter is advanced into the uterine cavity. The outer sheath serves to stabilize the softer and more flexible inner catheter, which can be retracted into the outer sheath for negotiation of the cervical canal.

For difficult transfers, it is possible to use the outer sheath independent of the inner catheter, advancing only the outer sheath through the endocervical canal, tailoring the curve to the specific cervical anatomy, and one it is placed to bring the loaded soft inner catheter. After the embryos are discharged, only the transfer catheter should be removed, in order to facilitate retransferring retained embryos, if needed. A malleable stylet can be used to place the outer sheath of the echogenic catheter. Then the stylet can be removed, and the inner soft catheter inserted.

- Catheter loading technique and load volume: In Phase I, we loaded the catheter following the three drop technique, because some authors suggested that the air bubbles mark the position of the embryos, and protect against lost or entrapping with mucus (Antunes et al., 2015; Krampl et al., 1995; Moreno et al., 2004). Embryos were loaded, into a rinsed catheter in 20-30 $\mu$ l of medium between 2 small air bubbles, which helped to the US catheter visualization. Even though, there was no enough evidence to support the use of air bubbles (Mansour, 2012).

In Phase II, when we introduced the echogenic catheters air bubbles were no longer needed. Furthermore, some authors suggested that a large volume of transfer media or air $(60 \mu \mathrm{l})$ could cause the expulsion of the embryos (Mansour, 2012). Therefore, we decided to use a continuous fluid column, without air bubbles, containing the embryos in a drop of 20-30 $\mu$ l of ET medium, as recommended by Schoolcraft et al. (2001) and Coroleu et al. (2000).

Later, we started to use Hyaluran-enriched transfer medium (Embryoglue, Vitrolife). Then, we reintroduce the three drop technique in order to economize medium, or the dilution of the Hyaluran-enriched transfer medium in the pre-wash medium. We rinsed and filled the catheters with regular transfer medium, added an air bubble, then $30 \mu \mathrm{l}$ of Hyaluran-enriched transfer medium with the embryos and then another air bubble. The outcomes were not affected. Similarly, two prospective randomized trials investigated the effect of air bubbles in the ET catheter and concluded that they had no negative effect (Krampl et al., 1995; Moreno et al., 2004).

- $\quad$ Types of catheter: In 1999, a survey of clinicians rated the choice of catheter as the third most important variable in ET (Kovacs, 1999). Some studies have evaluated the relationship between the type of the ET catheter and the outcomes of ART (Abou-Setta et al., 2005; Buckett 2006; Coroleu et al., 2006; Karande et al., 2002; Meriano et al., 2000; Schiewe et al., 2005). Two systematic review and meta-analysis evaluating firmness of the ET catheter concluded that soft ET catheters result in a significantly higher PR as compared with firm catheters (Abou- Setta et al., 2005; Buckett, 2006). But, some authors found that passing soft catheters through the cervical canal is often difficult. Soft catheters were associated with a higher incidence of difficult transfer, blood and contamination were present more frequently. Maybe, because soft catheters increased the use of a tenaculum (Abou-Setta et al., 2005).

To bypass this problem, a coaxial catheter system including an inner soft catheter with an echo-dense tip for ultrasound-guided ET was designed, Cook Echo-Tip, with an echogenic band at its tip. Wallace Sureview with echogenicity throughout the inner catheter (provided with small air bubbles) is another echogenic option that now exists. Two RCT studies concluded that the use of the echogenic catheters simplifies US guided ET (Coroleu et al., 2006; Karande et al., 2002). The echo-dense tip of the Cook Echo-Tip catheter was easily seen with US guidance, minimizing catheter movement to identify the tip (Karande, 2002).

Modified transfer catheters comprise a fine wire guide into the proximal two-thirds of the inner sheath or transfer catheter, allowing rigidity and preventing bending, but maintaining the soft nature of the distal third available (Cook EchoTip and Sure-Pro Ultra). They are available with obturator or stylet.

When comparing the types of catheters for better ET, soft and echogenic catheters are the obvious recommendation, as they facilitate the procedure (Abou-Setta et al., 2005; Allahbadia et al., 2010; Buckett, 2006; Coroleu et al., 2006; Karande et al., 2002; Schiewe et al., 2005).

During our ET standardization process, we used a wide diversity of catheters at the beginning of Phase I (Figure 1).Variations in catheter design comprised stiff and soft materials, presence of outer sheath, malleability and memory, and presence of obturator or stylet for difficult transfers.

With time, our preference for soft catheters clearly increased. Rigid catheters were associated with bleeding, trauma, and stimulation of uterine contractions. In 2000, we introduced in our practice the soft and echogenic catheter EchoTip (Cook Medical, USA) and noticed that the frequency of difficult transfers decreased (Figure 2). Since 2007, we also used the Wallace Sureview and Sure-Pro Ultra. 
Echogenic catheters allowed adequate monitoring via abdominal US with small movements in the transverse plane, decreasing the frequency of difficult transfers (Fig. 2). Echogenicity allowed to direct and manipulate catheter through the cervix more accurately and avoided traumatizing and stimulating it, reduced damage to the endometrium and the number of attempts, preventing bleeding and uterine contractions.

It is very important to avoid difficult transfers. Lesny et al. (1998) performed mock transfer with $30 \mu$ of opaque medium in 14 oocyte donors and found that with easy mock transfers the medium remained in the fundus for 45 minutes, but with difficult mock transfers the contrast moved from the fundus. Strong, random uterine contractions were seen to the cervix and the tubes.

Matorras et al. (2004) suggested that the time interval from catheter loading to its injection into the uterine cavity is a factor that generate variations in the CPR and IR. Because of the effect of ambient conditions exposure. They highlighted the importance of reducing handling times in the ET, thus increasing pregnancy rates. The use of echogenic catheters clearly reduced our procedure time, as was reported previously (Coroleu et al., 2006; Matorras et al., 2004; Tiras \& Cenksoy, 2014).

- $\quad$ Distance from fundus: A retrospective analysis of 5,055 US-guided ETs showed that ongoing PRs where higher if ET was performed at a distance $<1.0 \mathrm{~cm}$ from the fundus (Tiras et al., 2010). Echogenic catheters allowed to visualize the catheter tip within the uterus for placing embryos 1.0 to $1.5 \mathrm{~cm}$ from the fundus in Phase I, and 1.5 to 2.0 in Phase II, preventing clinical touch, which can induce uterine contractions (Antunes et al. 2015; Coroleu et al., 2002; Frankfurter et al., 2004; Tiras et al., 2010). Martínez \& Ruhlman (2015) reported that the visualization of the tip is better with the Echo Tip catheter.

- Withdrawal of ET catheter: Some authors recommend to wait for more than one minute to discharge embryos from the catheter, leaving the catheter in place to allow the fluid to disperse (Kovacs, 1999), or wait for withdrawal of the catheter so that the uterus can stabilize (Al-Shawaf et al., 1993; Mansour \& Aboulghar, 2002; Wisanto et al., 1989). Others authors recommend waiting only 10-20 seconds (Antunes et al., 2015). In our practice, the physician rotated $180^{\circ}$ the catheter, paused, and withdrawn it slowly, keeping the finger pressure on the plunger of the syringe, to prevent the effects of negative pressure.

- Checking: The ET catheter was returned to the laboratory to check for retained embryos. If found, they were retransferred immediately.

- Post-ET interventions: A Cochrane review showed that there is not enough evidence to support bed rest, mechanical pressure closing the cervical canal, and to use of fibrin sealant on the ET medium (Abou-Setta et al., 2014).

Contraction frequency at the time of ET is correlated with anxiety levels. High-frequency uterine contractions on the day of ET may reduce the pregnancy rate, by expelling embryos out of the uterine cavity (Fanchin et al., 2000). Additionally, some studies showed that fertility treatment dropout is associated with psychological factors (Braverman, 2012; Domar et al., 2010; Urdapilleta, 2015). Fertility programs as ours are including some anti-stress therapies like acupuncture and relaxation approaches, as coadjuvant treatments, because there are some recent evidence-based reports showing that they could be a safe and effective tool to control anxiety (Bungum \& Bungum, 2009; Braverman, 2012; Domar et al., 2011; Urdapilleta, 2015; Zheng et al., 2012). We believe in a comprehensive patient care. Patient's understanding and mind relaxation will allow the patient to actively collaborate with the procedure, and maximize her probability of success.

Some studies suggest CPR and IR are related to the degree of difficulty of the ET (Fanchin et al., 1998; Lass et al.,1999; Sallam et al., 2002). Mansour et al. (1990) found that there were 1.7 times more pregnancies on easy and intermediate transfers than with difficult ET. In our practice, the diversity of catheters used (Figure 1) and the percentage of difficult transfers decrease as increased the use of echogenic catheters (Figure 2).

Standardization and continuous quality improvement have depended on a data-driven process constantly monitored, as recommended by ACOG (2012), which allowed to prevent difficult transfers and contribute to improving outcomes.

The best measure of efficiency of our ET protocol may be illustrated by the improvement of CPR and LBR at UNIFERTES during the study years. CPR per transfer and LBR per clinical pregnancy are $72,6 \%$ and $80 \%$ respectively, in women under 35 years old, with Elective Single Blastocyst Transfer. But, these results cannot only be attributable to the use of echogenic catheters. There have also been great improvements in ovarian stimulation protocols and embryo culture.

- The outcomes depend on a number of optimal conditions, but ET is a crucial part of the IVF treatments. To standardize the ET protocol allowed a quicker and easier transfer. The use of echogenic catheters simplified ET procedures guided by abdominal US (table 2 ).

\section{CONCLUSION}

- The choice of echogenic catheters clearly facilitated the standardization of ET method.

- The echogenic catheters simplified US-guided ET, minimizing the need for catheter movement to identify the tip.

- Ease of ET was clearly related to echogenic catheters.

\section{CONFLICT OF INTERESTS}

No conflict of interest have been declared.

\section{Corresponding author:}

Maria Teresa Urbina

Unidad de Fertilidad UNIFERTES, Caracas, Venezuela

E-mail: mturbina@unifertes.com

\section{REFERENCES}

AAbou-Setta A, Al-Inany H, Mansour RT, Serour G, Aboulghar $M$. Soft versus firm embryo transfer catheters for assisted reproduction: a systematic review and meta-analysis. Hum Reprod 2005; 20: 3114-21.

Abou-Setta AM, Mansour RT, Al-Inany HG, Aboulghar MM, Aboulghar MA, Serour GI. Among women undergoing embryo transfer, is the probability of pregnancy and live birth improved with ultrasound guidance over clinical touch alone? A systematic review and meta-analysis. Fertil Steril 2007; 88:333-41.

Abou-Setta AM, Peters LR, D'Angelo A, Sallam HN, Hart RJ, Al-Inany HG. Post-embryo transfer interventions for assisted reproduction technology cycles. Cochrane Database Syst Rev. 2014;8: CD006567.

ACOG Committee on Patient Safety and Quality Improvement. ACOG Committee Opinion No. 526: Standardization of practice to improve outcomes. Obstet Gynecol 2012;119:1081-2.

Allahbadia GN, Kadam K, Gandhi G, Arora S, Valliappan JB, Joshi A, Allahbadia S, Wolman I. Embryo transfer using the Sureview catheter-beacon in the womb. Fertil Steril 2010; 93:344-50. 
Al-Shawaf T, Dave R, Harper J, Linehan D, Riley P, Craft I. Transfer of embryos into the uterus: how much do technical factors affect pregnancy rates? J Assist Reprod Genet $1993 ; 10: 31-6$.

Antunes R, Mancebo AC, Areas PC. Técnica de Transferencia. In Perez E, ed. Red Latinoamericana de Reproducción Asistida. Técnica de transferencia. Manual de procedimientos clínicos en reproducción médicamente asistida. 2015. p 150-1.

Braverman AK. The relationship between stress and in vivo fertilization outcome. In: Gardner DK, Weissman A, Howles CM, Shoham Z, eds. Textbook of Assisted Reproduction Techniques. Fourth Edition. USA: Informa Healthcare; 2012. pp.434-40

Brown J, Buckingham K, Abou-Setta AM, Buckett W. Ultrasound versus 'clinical touch' for catheter guidance during embryo transfer in women. Cochrane Database Syst Rev. 2010; 1:CD006107.

Buckett WM. A review and meta-analysis of prospective trials comparing different catheters used for embryo transfer. Fertil Steril 2006; 85:728-34.

Buckett WM. A meta-analysis of ultrasound guided versus clinical touch embryo transfer. Fertil Steril 2003; 4:103741.

Bungum L, Bungum M. Embryo transfer. In: Gardner DK, Weissman A, Howles CM, Shoham Z, eds. Textbook of Assisted Reproduction Techniques. Third Edition. USA: Informa Healthcare; 2009. pp. 693-9.

Coroleu B, Barri PN, Carreras O. The influence of depht of embryo replacement into the uterine cavity on implantation rates after IVF: a controlled, ultrasound guided study. Hum Reprod 2002; 17:341-6.

Coroleu BA, Barri P, Carreras O, Belil I, Buxaderas R, Veiga $A$, Balasch. Effect of using an echogenic catheter for ultrasound-guided embryo transfer in an IVF programme: a prospective, randomized, controlled study. Hum Reprod 2006; 21:1809-15.

Coroleu B, Carreras O, Veiga A, Martell A, Martinez F, Belil I, Hereter L, Barri PN. Embryo transfer under ultrasound guidance improves pregnancy rates after in-vitro fertilization. Hum Reprod 2000;15:616-20.

De Placido G, Wilding M, Strina I, Mollo A, Alviggi E, Tolino A, Colacurci N, De ML, Marino M, Dale B. The effect of ease of transfer and type of catheter used on pregnancy and implantation rates in an IVF program. J Assist Reprod Genet 2002; 19:14-8.

Domar AD, Smith K, Conboy L, Iannone M, Alper M. A prospective investigation into the reasons why insured United States patients drop out of in vitro fertilization treatment. Fertil Steril 2010; 94:1457-9.

Domar AD, Rooney KL, Wiegand B, Orav EJ, Alper MM, Berger BM, Nikolovski J. Impact of a group mind/body intervention on pregnancy rates in IVF patients. Fertil Steril. 2011; 95:2269-73.

Dorn C, Reinsberg J, Schlebusch H, Prietl G, van der Ven $H$, Krebs D. Serum oxytocin concentration during embryo transfer procedure. Eur J Obstet Gynecol Reprod Biol
1999; 87:77-80.

Egbase PE, Al-Sharhan M, Grudzinskas JG. Influence of position and length of uterus on implantation and clinical pregnancy rates in IVF and embryo transfer treatment cycles. Hum Reprod 2000; 15:1943-6.

Fanchin R, Gellman S, Righini C, Ayoubi J-M, Olivennes F, Frydman R. Uterine contraction frequency at the time of embryo transfer (ET) is correlated with anxiety levels. Fertil Steril 2000; 74: S252.

Fanchin R, Righini C, Olivennes F, Taylor S, De Ziegler D, Frydman R. Uterine contraction at the time of embryo transfer alter pregnancy rates after in vitro fertilization. Hum Reprod 1998; 13:1968-74.

Frankfurter D, Trimarchi JB, Silva CP, Keefe DL. Middle to lower uterine segment embryo transfer improves implantation and pregnancy rates compared with fundal embryo transfer. Fertil Steril 2004; 5:1273-7.

Gambadauro P, Navaratnarajah R. Reporting of embryo transfer methods in IVF research: a cross-sectional study. Reprod Biomed Online 2015; 2:137-43.

Goudas VT, Hammitt DG, Damario MA, Session DR, Singh AP, Dumesic DA. Blood in the embryo transfer catheter is associated with decreased rates of embryo implantation and clinical pregnancy with the use of in vitro fertilization-embryo transfer. Fertil Steril 1998; 70:878-82.

Karande V, Hazlett D, Vietzke M, Gleicher N. A prospective randomized comparison of the Wallace catheter and the Cook Echo-Tip catheter for ultrasound-guided embryo transfer. Fertil Steril 2002; 4:826-30.

Karande VC, Morris R, Chapman C, Rinhart J, Gleicher N. Impact of the "Physician factor" on pregnancy rates in a large assisted reproductive technology program: do too many cooks spoil the broth? Fertil Steril 1999; 71:1001-9.

Kovacs GT. What factors are important for successful embryo transfer after in vitro fertilization? Hum Reprod 1999; 14:590-2.

Krampl E, Zegermacher G, Eichler C, Obruca A, Strohmer $\mathrm{H}$, Feichtinger $\mathrm{W}$. Air in the uterine cavity after embryo transfer. Fertil Steril 1995;63:366-70

Lass A, Abusheikha N, Brinsden P, Kovacs GT. The effect of a difficult embryo transfer on the outcome of IVF. Hum Reprod 1999; 14:2417.

Lesny P, Killick SR, Robinsom J, Raven G, Maguiness SD. Junctional zone contractions and embryo transfer: it is safe to use a tenaculum? Hum Reprod 1999; 14:2367-70.

Lesny P, Killick SR, Tetlow RL, Robinson J, Maguiness SD. Embryo transfer-can we learn anything new from the observation of junctional zone contraction. Hum Reprod $1998 ; 13: 1540-6$.

Mains L, Van Voorhis BJ. Optimizing the technique of embryo transfer. Fertil Steril 2010; 94:785-90.

Mansour R, Aboulghar M, Serour G. Dummy embryo transfer: a technique that minimizes the problems of embryo transfers and improves the pregnancy rate in human in vitro fertilization. Fertil Steril 1990; 54:678-81. 
Mansour R. Embryo transfer technique. In: Gardner DK, Weissman A, Howles CM, Shoham Z, eds. Textbook of Assisted Reproduction Techniques. Fourth Edition. USA: Informa Healthcare; 2012. pp. 263-77.

Mansour RT, Aboulghar MA, Serour GI, Amin YM. Dummy embryo transfer using methylene blue dye. Hum Reprod 1994; 9:1257-9.

Mansour RT, Aboulghar MA. Optimizing the embryo transfer technique. Hum Reprod 2002; 17:1149-53.

Martínez G, Ruhlman C. Elección del catéter de transferencia embrionaria. In Perez E, ed. Red Latinoamericana de Reproducción Asistida. Técnica de transferencia. Manual de procedimientos clínicos en reproducción médicamente asistida. 2015. p 187-8.

Matorras R, Mendoza R, Exposito A, Rodríguez Escudero FJ. Influence of the time interval between embryo catheter loading and discharging on the success of IVF. Hum Reprod 2004; 19:2027-30.

McNamee PI, Huang TTF, Carwile AH, Chun BHH, Kosasa TS, Morton C, Terada FM Significant increase in pregnancy rate achieved by vigorous irrigation of endocervical mucus prior to embryo transfer with the wallace catheter in an IVF-ET program Fertil Steril 1997; 68: S228-9.

Meldrum DR, Chetkowski R, Steingol KA, De Ziegler D, Cedars MI, Hamilton M. Evolution of a highly successful in vitro fertilization embryo transfer program. Fertil Steril 1987 ; 48:86-93.

Meriano J, Weissman A, Greenblatt EM, Ward S, Casper RF. The choice of embryo transfer catheter affects embryo implantation after IVF. Fertil Steril 2000;74:678-82.

Michael E, Ahmady A. The use of a cytobrush in cervical canal preparation for embryo transfer procedures. Fertil Steril 2005;84:S357

Moreno V, Balasch J, Vidal E, Calafell JM, Cívico S, Vanrell JA. Air in the transfer catheter does not affect the success of embryo transfer. Fertil Steril 2004;81:1366-70.

Peron J, Pond GR, Gan HK, Chen EX, Almufti R, Maillet D, You B. Quality of reporting of modern randomized controlled trials in medical oncology: a systematic review. J Natl Cancer Inst 2012; 104:982-9.

Sallam HN, Agameya AF, Rahman AF, Ezzeldin F, Sallam AN. Ultrasound measurement of the uterocervical angle before embryo transfer: a prospective controlled study. Hum Reprod 2002; 17:1767-72.

Sallam HN, Sadek SS. Ultrasound-guided embryo transfer: a meta-analysis of randomized con- trolled trials. Fertil Steril 2003; 80:1042-6.

Sallam HN, Agameya AF, Rahman AF, Ezzeldin F, Sallam AN. Impact of technical difficulties, choice of catheter, and the presence of blood on the success of embryo transfer--experience from a single provider. J Assist Reprod Genet. 2003; 20:135-42.

Schiewe MC, Miller F, Hubert GD, Butalos RP. Comparative echogenicity of various soft-tipped embryo transfer catheters. Fertil Steril 2005; 84:S349-50.

Schoolcraft WB, Surrey ES, Gardner DK. Embryo transfer: Techniques and variables affecting success. Fertil Steril $2001 ; 76: 863-70$.

Tiras B, Cenksoy O. Practice of Embryo Transfer: Recommendations during and after. Semin Reprod Med 2014; 32:291-6.

Tiras B, Polat M, Korucuoglu U, Zeyneloglu HB, Yarali H. Impact of embryo replacement depth on in vitro fertilization and embryo transfer outcomes. Fertil Steril 2010; 94:1341-5.

Turner L, Shamseer L, Altman DG, Weeks L, Peters J, Kober T, Dias S, Schulz KF, Plint AC, Moher D. Consolidated standards of reporting trials (CONSORT) and the completeness of reporting of randomised controlled trials (RCTs) published in medical journals. Cochrane Database Syst Rev. 2012;11:MR000030.

Urdapilleta L. Apoyo psicológico. In Perez E, ed. Red Latinoamericana de Reproducción Asistida. Técnica de transferencia. Manual de procedimientos clínicos en reproducción médicamente asistida. 2015. p 144-5.

Wang JL, Sun TT, Lin YW, Lu R, Fang JY. Methodological reporting of randomized controlled trials in major hepato-gastroenterology journals in 2008 and 1998: a comparative study. BMC Med Res Methodol 2011;11:110.

Wisanto A, Janssens R, Deschacht J, Camus M, Devroey $P$, Van Steirteghem AC. Performance of different embryo transfer catheters in a human in vitro fertilization program. Fertil Steril 1989; 52:79-84.

Woolcott R, Stanger J. Potentially important variables identified by transvaginal ultrasound-guided embryo transfer. Hum Reprod 1997; 12:963-6.

Yao Z, Vansteelandt S, Van der Elst J, Coetsier T, Dhont M, De Sutter P. The efficacy of the embryo transfer catheter in IVF and ICSI is operator-dependent: a randomized clinical trial. Hum Reprod 2009; 24:880-7.

Zheng $\mathrm{CH}$, Huang GY, Zhang MM, Wang W. Effects of acupuncture on pregnancy rates in women undergoing in vitro fertilization: a systematic review and meta-analysis. Fertil Steril 2012; 97: 599-611. 